\title{
Teachers' Perspectives on Task-Based Language Teaching: A Case Study at International Islamic University Malaysia
}

\author{
Asma Musazay \& Madihah Khalid*
}

\begin{abstract}
The term task-based language teaching (TBLT) is widely used in the context of second language acquisition in terms of a curriculum which promotes actual language use. However, little research has been conducted in Malaysia regarding TBLT and its implicit method. This study, therefore, aims to explore and research the perceptions of CELPAD teachers towards TBLT, at the International Islamic University Malaysia (IIUM). The research aims to determine the level of awareness, understanding, and the perception that teachers have towards this method, as well as whether they employ it in their classrooms or not. The study employs a qualitative methodology, namely 'case study'. The data collection instruments consist of interviews of three randomly selected instructors at CELPAD, one for each level ranging from level 4-6. The overall findings show that the CELPAD teachers possess a clear understanding of TBLT, agreeing that TBLT is beneficial. However, they are still unsure of the advantages of using it in the classroom. Furthermore, there is some measure of fear in adopting task-based language teaching fully primarily as a result of the problems they face pertaining to the end of semester assessment; the English Placement Test. As a result, it is found that some teachers use a mixed approach of both TBLT and traditional teacher-centered approach.
\end{abstract}

Keywords: Task-Based Language Learning, Case Study, Second Language Acquisition, Pedagogy

\section{Introduction}

The use of task-based and communicative language teaching of English is highly encouraged and recommended by the Malaysian Ministry of Education. The national curriculum of Malaysia is regarded as a communicative curriculum (Malaysian Ministry of Education [MOE], 2011), i.e. "an organization of Communicative Language Teaching (CLT) around a specification of communication tasks" in Richards \& Rodgers, 2001, p.164. As such, the Malaysian National curriculum aims to develop students "with the ability to communicate accurately and effectively in the most common English language activities they may be involved in" (Richards \& Rodgers, 2001, p.230).

A wide array of methods have been progressively established throughout the years for students undertaking the second language instruction. To analyze and elaborate on

\footnotetext{
${ }^{*}$ Kulliyyah of Education, International Islamic University Malaysia
} 
them collectively would be far beyond the scope of this research however. This study instead focuses on exploring the Centre for Languages and Pre-University Academic Development (CELPAD) of International Islamic University in Malaysia (IIUM) teachers' perspective and attitude towards task based language teaching. Currently, CELPAD has fully applied TBLT in all its respective levels (from 1 to 6 ) in order to encourage the flow of communication in the classroom and garner as much possible benefit as possible from facilitating this form of approach within their classroom philosophy.

Recent development in language teaching methods have heightened the need to further apply research on various other countries and classroom settings. The term taskbased language teaching is widely used in the context of second language acquisition in terms of curriculums which promotes actual language use. According to Nunan (2003), in conducting a study based on interviews with teachers, teacher educators and ministry officials, task based language teaching emerged as a key and central concept from a study of curriculum guidelines and syllabi in Asia-Pacific countries including but not limited to Japan, Vietnam, China, Hong Kong, Korea and Malaysia (Nunan, 2003).

Many researchers have conducted research on the task-based language teaching or task-based communicative learning (e.g., Nunan, D. (1991). With the researchers' different researches on further producing better communicative performance and language acquisition through task-based language teaching; little research has been done in Malaysia developing the teaching method and further understanding TBLT clearly.

However, literature related to TBLT indicates that despite its benefits in formulating participatory learning culture, it has yet to be studied thoroughly or proven empirically in terms of its classroom practice in foreign language learning context (Carless, 2004). CELPAD implements TLBT and therefore, it is very significant to know how this approach affects the process of learning among the students. An indication shows through previous research that some of the teachers have not attained an adequate understanding of task-based language teaching. As such, in light of the above, this paper will look into exploring CELPAD teachers' perspectives of Task-based language teaching by means of analyzing their perception and understanding of TBLT and how they implement this concept or whether they avoid it altogether and further explore and derive the reasons behind its implementation or avoidance.

\section{Task-Based Language Teaching (TBLT)}

Task-based language teaching as defined by Ellis (2003) and Nunan (2004) is a communicative approach to language teaching in which tasks are used to facilitate language acquisition. Although the implementation of TBLT has been going on for decades, there is little research demonstrating that it has been implemented on a task-based syllabus as a whole or that the teachers fully adapted to the teaching of the tasks (Carless, 2004). According to Lindsay and Knight (as cited by Vystavělovz 2009), TBL is promoted by giving the students tasks to complete as they are using the target language. "Tasks are believed to foster processes of negotiation, modification, rephrasing, and experimentation that are at the heart of second language learning" (Richards \& Rogers: 228). 
The task-based framework consists of three main phases; these phases are pre-task, task cycle and language focus.

1. Pre-task: The teacher introduces the topic to the class and gives them directions on what they need to do. Ellis (2006) states that the first phase is pre-task and explains the various activities that teachers and students can carry out before they start the task.

2. Task Cycle: It presents the students with a broad experience of language in use.

It consists of three elements:

a. Task: The students work on a task simultaneously, in groups or in pairs while the teachers monitors and offers support.

b. Planning: It forms the central part of the cycle and comes after the task but before the report. Here, students orally or in a written form explain to the class that what happening during their task. The teacher is available to advice the students about the language in order to boost their learning capabilities.

c. Report: It is an important stage in which the students report their findings to the class while the teacher may give them a quick feedback about their content. This phase also aims at providing some pedagogic goals like encouraging feedback and reflection, etc. This helps the students to improve their language.

3. Language Focus: This allows the learners to examine the language forms in the text and look in detail at the use and the meaning of lexical items they have noticed (Willis, 1996, p.75). Language focus has two components:

1. Analysis: In this phase, parts of the text are highlighted by the teacher for analysis by the students. The teacher can then tell the learners to point out the main features of the text. This can broaden the understanding of the learners by reflecting upon the language.

2. Practice: Finally, in this phase, the students practice the language areas as directed by the teacher based upon the needs of the learner. The practice increases the inquisition of language and the self-confidence of the learners.

In task-based language teaching, "language is treated primarily as a tool for communicating rather than an object for study or manipulation" Ellis (2004: 23). For Nunan (2004: 17), the task-based language teaching is

...the deployment of grammatical knowledge to express meaning, highlighting the fact that meaning and form are highly interrelated, and that grammar exists to enable the language user to express different communicative meanings......tasks differ from grammatical exercises in that learners are free to use arrange of language structures to achieve task outcomes...

As indicated in the quote above, that the task and grammar are two completely different language acquisition methods. To communicate through the usage of grammar lessons the student has less freedom to express as opposed to a casual classroom activity that also includes communication but the student has further freedom to utter and discuss without feeling limited to the language and word usage. With the latter the student has no rules to follow and would thus be able to exercise the ability to express in more than one way. 
The discussed topics and lessons in task-based environments are generally those of interest to the learner. Task-based instruction encourages learning by doing and thereby motivating the students through activities that makes them the core in the learning process. Task-based learning involves those instructions in which classroom activities are tasks similar to those which learners may engage in outside the second language classroom. Tasks may be complex, for example, creating a school newspaper or easier such as making a hotel reservation (Lightbrown \& Spada, 1999).

Nunan (2004) describes the task as "a piece of classroom work which involves learners in comprehending, manipulating, producing or interacting in the target language while their attention is principally focused on meaning rather than form" (p. 10). Prabhu (1987) defines task as "an activity which requires learners to arrive at an outcome from given information though some process of thought, and which allows teachers to control and regulate that process" (p.24). Skehan (as cited in Yim, Sue, n.d) describes the two extremes of tasks which are: structure oriented tasks and communicatively oriented tasks. The structure oriented approach could also be referred to as the weak form of TBLT, while the communicatively oriented approach is referred to as the strong form of TBLT. The first emphasizes on the linguistic form as for the latter emphasizes on the meaning over form. Some TBLT proponents argue that through tasks, the learners' attention is linguistically drawn in the context i.e. they focus on form and to focus on the form, communication is a prime concern. (McDonough \& Chaikitmongkol, 2007).

Much of the research carried out on task based language teaching focused on other societies and contexts, but has gained interest from a number of other EFL countries ( $\mathrm{Li}$, 1998; Bax, 2003; Ellis, 1996; Littlewood, 2007). However, little research has been conducted in Malaysia regarding (TBLT) and its implicit method, therefore elucidating and making clear the rationale behind the conducting of this study at IIUM. Furthermore, TBLT as a language learning tool is rather under-researched within the CELPAD classroom. In order to analyze the rate of success or otherwise, it is a necessary mandate to learn the CELPAD teachers' perspective towards this approach, upon which rests the premise of this thesis.

According to Cunningham and Cunningham (2002), engagement is quite likely the most common term used in discourse regarding the intrinsic relationship spanning the intertwined concepts of motivation and learning (p.89). Along such a paradigm, numerous studies have been undertaken, only to reveal that in order to bring about engaged students in a classroom setting, the teacher must -intuitively enough- approach with lessons that spark, ignite and capture their shared and individual interest. A great number of languagelearning tools have been introduced and used in contemporary times. One of the most prominent task-based language teaching comprises of nature of the instructional process which promotes communicative tasks and, in fact, requires of the student to engage in the classroom (Nunan, 1991).

Task-based Language Teaching (TBLT), also known as Task-based language learning or Task-based instruction was first structured by Dave Willis and Jane Willis (Richards \& Rogers, 2001). Yet, it first emerged in the early 1980s (Byram, 2000). TBLT method was popularized by N.S. Prabhu, while working on Bangalore Project, which consisted of a small number of elementary and secondary English classes in India for five years. Prabhu believed that students may learn more effectively when their minds are focused on the task, rather than on the language they are using (Prabhu, 1987; as cited in 
Littlewood, 2004). Other major scholars who have contributed to this field by their research include Teresa P. Pica and Michael Long.

TLBT constitutes a branch of Communicative language teaching (CLT). Brown (2007) defines CLT as "an approach to language teaching methodology that emphasizes authenticity, interaction, student-centered learning, task based activities, and communication for the real world, meaningful purposes" (Brown: 378). Savignon (2002) writes that "CLT refers to both processes and goals in classroom learning" and that "the central theoretical concept in communicative language teaching is communicative competence" (p.1).

Brown (2007) also offers four interconnected characteristics of CLT:

1. Classroom goals are focused on all of the components of CC (communicative competence) and not restricted to grammatical or linguistic competence.

2. Language techniques are designed to engage learners in the pragmatic, authentic, functional use of language for meaningful purposes. Organizational language forms are not the central focus but rather aspects of language that enable the learner to accomplish those purposes.

3. Fluency and accuracy are seen as complimentary principles underlying communicative techniques. At times fluency may have to take on more importance than accuracy in order to keep learners meaningfully engaged in language use.

4. In the communicative classroom, students ultimately have to use the language, productively and receptively, in unrehearsed contexts. (p. 241)

Dave \& Jane Willis espoused the effective use of tasks as a language learning tool and strongly supported its implicit significance, while further highlighting how it plays a substantial role in the language learning ability of the student. The method utilized is based on the use of tasks as the core unit of planning and instruction in language teaching (Richards \& Rogers, 2001); in other words tasks are the foundation of their teaching curriculum.

Long (1985) defines task as:

A piece of work undertaken for oneself or for others, freely or for some reward. Thus examples of tasks include painting a fence, dressing a child, filling out a form, buying a pair of shoes, making an airline reservation, borrowing a library book, taking a driving test, typing a letter, weighing a patient, sorting letters, making a hotel reservation, writing a cheque, finding a street destination and helping someone across a road. In other words, by 'task' is meant the hundred and one things people do in everyday life, at work, at play and in between.

We can observe that this definition is non-technical. Meaning when the teacher applies it to a classroom setting, the definition of a task becomes pedagogical in nature. So moving on now to defining task in a pedagogical perspective. Skehan (1998) whose definition of task is well-accepted, defines a task using four criteria; Meaning is primary, it works toward a goal, it is outcome-evaluated, and it is related to the world outside the classroom. The task-based teaching was introduced in Hong Kong as part of the Target-Oriented Curriculum (TOC) reform in the 1990s, which defines task in terms of five main elements (Clark, Scarino, \& Brownell, 1994; Curriculum Development Council, 1997):

1. A purpose or underlying real-life justification for doing the task, involving more than simply the display of knowledge or practice of skills 
2. A context in which the task takes place, which may be real, simulated or imaginary

3. A process of thinking and doing required in carrying out the task, stimulated by the purpose and the context

4. A product or the result of thinking and doing, which may be tangible or intangible

5. A framework of knowledge, strategy and skill used in carrying out the task.

Nunan (1989) defines a 'task' as:

...the communicative task [is] a piece of classroom work involving learners in comprehending, manipulating, producing or interacting with the target language while their attention is principally focused on meaning as opposed to form. The task should also have a sense of completeness, in being able to stand alone as a communicative act in its own right. (1989: 10)

According to Jane Willis (Richards \& Rogers, 2001), the task based language approach augments the learning process by allowing students to effectively become more involved. This is brought about by means of exposing the student to meaningfully designed tasks forcing him to communicate, which results in learning. Students are placed within the circumstances and conditions asserted by teachers, permitting them to utilize the limited language skills they possess; and with practice and time a student becomes more comfortable with language than at the initial onset of instruction. One of the main intentions behind applying a task based language teaching method in second language classrooms is to stimulate and enhance communication between students via the chosen target language in a safe setting that facilitates their motivation, and creates a pervasive atmosphere where they can apply what they have learned without feeling judged (Vystavělová, 2009).

The task-based learning provides the learner with an active-role and thus participating in and creating activities increases their motivation towards learning. TBL gives more room to the learner to display creativity and thinking through actions. As such, it plays an important role in current language pedagogy (Solares, 2006). The activities of the task-based method enforces a realistic goal on learners; by completing the task successfully one is theoretically able to actually make use of the focused language to associate meaning, and in doing so the expected outcome will in turn enhance linguistic standards as well. (Skehan, 1998). The task-based learning also encourages peer feedback. The students can present their own thoughts or evaluate those of others. Everyone can take part in the evaluation of strengths and weaknesses that generate out of work within the classroom. This produces development of critical awareness among the students $(\mathrm{Ki}$, 2000).

It is safe to deduce from the previous studies that learning strategies promote and play a rather big role in the achievement levels of students. This is also supported by Pintrich \& De Groot (1990). This is also reflected elsewhere, for according to Zimmerman (1989:28) as found in Margolis \& McCabe (2003:2), it is student's self-regard with respect to their own academic potential that plays a central and key role to maintaining their motivation, drive and willingness to learn. 
In spite of task based language methods applied in language teaching, there are a myriad of challenges facing instructors when designing a lesson or constructing the proper materials for the class. This happens to have a very vague result as to how effective the task has been on the students.

Task-based language teaching, if implemented appropriately can provide an environment in which students interact in a manner that stimulates the learning process on their own. This is the true nature of task based language, for within its paradigm and approach, the student is accorded tasks to complete while making the best possible use of the target language (Lindsay \& Knight, 2006).

A number of studies have already been conducted by researchers on task-based language learning and teaching. These studies are related to the present study but varies in the sub-fields. For example, Rahman (2010) found that the oral communication that occurs in a classroom has an empirical success in the field of second language acquisition. However, his study does require different research methods (both quantitative and qualitative) in collecting data. According to his study, case studies actually provide a useful empirical data.

Even though there are various benefits in language learning contexts with TBLT, a task alone doesn't ensure that it is successful in implementation. Unless the instructor or the person in charge of the task performance thoroughly understands how tasks are actually performed in classroom. TBLT also suggests is more than just giving tasks to learners and evaluating their performance. It is very important for the teacher who is trying to implement TBLT successfully to have sufficient knowledge about the instructional framework related to its plant, procedure and assessment. (Joen, In-Jae \&Hahn, 2009).

A number of studies have been conducted in CELPAD, IIUM. For example, Mareena (1998) conducted a study on pre-sessional students learning style preferences. The study specifically explored the relationship between the preferred learning style and the students' cultural background. The results helped the instructors create instructional designs that are more student-centered and promoted self-directed learning. In another study (Noorliza, 2006); applied a quantitative study in CELPAD to show student selfefficacy and motivation to learn the English language. The results of the finding helped the teachers to find effective solutions to problems that arise regarding student motivation.

\section{The Present Study}

The major aim of the study is to explore CELPAD teacher's perception towards the TaskBased Language Teaching and highlight the reasons why they opt to avoid or implement this approach in their teaching. There will also be a minor focus on the levels in which TBLT is most likely utilized in CELPAD and further address the query as. The overall findings will help show reasons teachers choose to use or avoid TBLT in their classroom. The current study will further aid in identifying the challenges which they face as they apply this method to their students. Specifically, the research seeks to answer the following questions: 1) How do the CELPAD teachers' perceive the task-based language teaching? And 2) What reasons do the CELPAD teachers choose, or avoid, implementing task-based language teaching? 


\section{Method}

The current study is applying a case study approach to explain the teachers' perspective in CELPAD towards TBLT., interviews will be conducted in order to find out the teachers' perspective of TBLT. To be able to generate the data needed to assess the teacher's perspective, the interview questions were divided into three sections related to the research questions in this study. The rationale of using an interview in this subject is to be able to have a more accurate idea of how teachers' perceive TBLT regarding this topic.

The current study took place at the Centre for Languages and Pre-University Academic Development (CELPAD), International Islamic University Malaysia. The study focuses upon CELPAD that was established in 1983 to impart language courses among students. CELPAD represents a diverse and multicultural environment. It offers courses in English, Arabic and Bahasa Melayu along with some other language and bridging courses. The CELPAD has recently started implementing TBLT as a method of instruction in the classrooms.

Data were collected from three English teachers at CELPAD, one each from levels 4,5 , and 6 . This is because only they agreed to participate in the present study. While the potential participants were 9, it narrowed down to three due to the teachers not being available owing to their busy schedule, while others showed a lack of interest towards the current study. The three teachers interviewed come from rather diverse background of teaching in CELPAD, ranging from between two to twenty years of experience, educational background as well as having teaching experience in other institutes before settling in CELPAD, and thus yielding findings not particular to a specific stratum, but instead, well rounded and holistic in bearing and nature. The selection criteria was based on the teacher's knowledge of TBLT and generally those willing to participate in the interview.

The interview consisting of nine questions was divided into three sections. The first section contained demographic questions in order to gain information about the teachers' gender, age, teaching experience and the level he/she teaches in CELPAD. The second section dealt with the first research question, in order to review teachers' practical understandings of TBLT. The third section is related to the second research question, the reasons teachers choose to use or avoid task-based language teaching in their classroom.

For carrying out this research, a number of steps had to be taken. First, the permission was sought from Dean of Centre for Languages and Pre-University Academic Development (CELPAD) and consent was also taken from the teachers before conducting the study. Once the interviews were done they were transcribed and notes were taken. The data obtained from the structured interview were then analysed. The main findings are summarized in the next section.

\section{Results and Discussion}

After conducting thematic analysis of the data, a few themes emerged. Firstly, the view of the CELPAD teachers on the task-based language teaching was mainly what was discussed at first which led to discussing the challenges the teachers faced when using task-based language teaching in the classroom and how they ultimately tackled these challenges. In addition to that, the assessment of task-based performance was analyzed and was actually 
considered as part of the challenges that the teachers faced. The findings also further analyzed the reasons teachers choose or avoid using the task-based language teaching in their classroom. Lastly, the manner that the students eventually learned to acquire the language through the usage of task-based language teaching in the classroom.

\section{Communication in TBLT}

The subject took the personal stand that task based language teaching represented an intrinsic process through which the task is effectively handed to a student, where it was during the task itself that language became involved. The main concern is for the students; as teachers should not limit themselves to the books and vocabulary alone, but should rather think outside the box and cause students to exercise their language by means of communicating during the task. Teachers were in need of creating a safe environment and relatable tasks where the students were able and furthermore required and expected to utilize language as an outlet during said tasks without fear of repercussions, ridicule and the like. T1 asserts;

They read a sentence and I start asking them questions. And sometimes the questions change from one day to the next.. And some students are still looking here for the answer. They didn't actually hear the question.. They're trying to give you an answer. But they don't even know what the real question is... So what... What that student the way I see it. That students is thinking the language is somewhere here *points at book*... When I say no the language is here *points around*. The language is here right, and if you're thinking, if you're looking for your answer here, its you've got to get out of that thing, and that's what a task can do, get them away from the book. Think outside of the box. Get away from the book

For the interviewee, this would serve as taking some of the focus away from the language, thus placing it onto the task. A student would be forced to use language to accomplish the task and not find themselves stressed regarding the fluency of the language. Through further practice of the language during tasks, pressure would be relieved from the student, and thus the very act of sending and receiving by means of using said language would come naturally. As an example T2 asserts,

So for example, the task is maybe the students have to cook something and then they have to come up with recipes and all that. So you have specific... for example somebody needs this or transitional words firstly, secondly, thirdly, that is the lower level, so you ask them to quote and then decide what goes first then second and then next. So by doing that you will actually complete two things, one to exercise the language focus which is transitional for second whatever. And then secondly to ... do the non-language aspect of TBLT.

There is an understanding from T3 that in the classroom the focus is primarily on the student and their ability to communicate.

I know that the end of the day the students have to ... I know the focus is on the students because they have to work on their own. 
CELPAD teachers believe that Task-Based teaching holds benefits in terms of the learner's communication skills and interaction, and not merely within the classroom, but outside as well. T1 believes TBLT to be very comprehensive:

\section{I would call it communicative; I think that was the big umbrella term.}

The interviewer added in to what the teacher said with a question whether his statement implied that his main concern would be that the students are able to communicate on giving them a task; in which the interviewee agreed it to be his aim. In order for the students to complete the task the teacher gave them, they will have to discuss with one another which will be by default lead to communication. Thus, further enhancing their confidence and capability of tackling the upcoming tasks in their lessons.

After achieving significant long-term effects in learning the language; a matter which has long since been one of CELPAD main goals, CELPAD has further taken an immense amount of interest in introducing task based language teaching as the main instructional medium within its classrooms. T1 commented:

I think it fits in all levels, the way I see it, it's just that what you... What is produced has to be... You have to be allowed for diff production levels

T2 believes that:

It's a good idea to have a pure TBLT in the beginning level and when you actually move to a higher level then that's actually the time where you introduce structures.

By "all levels" here the teacher meant the CELPAD levels offered to the students from the first until the sixth and final level. The first level being the one where the students are just beginners in the language and as they move higher the skills of the students advances as well. The question arises whether the method of teaching can be used on the beginners as well, due to their lack of spoken English.

\section{Language Focus vs. Task Focus}

The first research question proposes studying teachers' perspective towards task-based language teaching. The findings of teachers exhibit that they have a comparatively clear understanding of task-based language teaching in general. The participants of the interview were all of the same opinion; in that the task-based language teaching for them was not aimed or aligned with the goal of linguistic accomplishments. Rather, it is inherent within the completion of a task that a student has gained respective competency in the language. Such an indirect approach is felt by them to be somewhat effective in regards to accomplishing the student's mastery of a language concept. As T1 puts it:

I mean the task itself is non linguistic. That's what I understood it to be. But that doesn't mean it doesn't involve in language. It has to involve in language. But the primary purpose is not the production of language. It's a fulfillment of a task. To do something.

When asked of their understanding, conception and knowledge of task-based language teaching, the first teacher interviewed, asserted the belief that task-based 
language teaching should not be a matter specifically 'linguistic' in nature, quoting a previous speaker, Tomlinson (2009) who provided a workshop on CELPAD on task based language teaching.

My perspective is that it's non linguistic in nature. This is from ... you know who it's from, right? This is from Tomlinson. He's the one who says it. It's non linguistic in nature. His definition is that it wasn't for linguistic purposes but from that task you can get language produced.

He further elaborated that although others may disagree with such an analogy regarding the manner in which he understood and explained task based language teaching, this went in line with what he believed in, and as such was indicative of his personal beliefs and stance on the respective issue. T1 went on asserting:

The sum of it is, what I know, are believed to be true is TBL or TBLT. The task is not linguistic. That's my sum of knowledge about that... It's not linguistic in nature. Give them something to do.

The second teacher T2 however, takes a decidedly simpler approach in that the task-based language teaching method that was first initiated by the former authority who stressed on the importance of following such an approach. T2 mentioned,

Umm... yea... TBLT started with the former Dean and then well it's a bit interesting because with TBLT we ask students to do tasks... And then in the task we ask students to actually exercise the sub skills any grammatical skills. For example if the task were speaking for example ok they need to interview people they need to use sub-skills uh sub-skills grammatical points whatever this course is related... Whatever it is... For them to actually complete the task also exercise the language.

The teacher implies here that the method is a mixture of both task and language focus which requires the students to complete the task given thoroughly. Lecturers were mandated to train intensively in the application of this approach and were highly anticipating changes in the level of language proficiency and education of students once the method was implemented and integrated in school teachings.

T3 takes two different approaches in teaching certain language skills. Further elaborating:

Normally I will apply a bit of traditional and a bit of modern teaching. The traditional part would probably be the grammar, I think they need drilling. That one has to stay as traditional. But in terms in discussion yes that one should be used in the modern in which is task-based language teaching. In terms of speaking I think it's more suitable for task based.

\section{Blended Approach}

As something of a sharp contrast, the second teacher (T2) prefers the utilizing of a rather mediocre teaching method which is strictly built on the basis of based on lessons either derived from the book or the curriculum; while furthermore pointing out that task based learning does not seemingly work well with each lesson, as in the case of grammar. 
Finally, the third teacher is found to prefer the usage of a much more traditional method. For instance, in the case of grammar, instead of applying a task-based method, she instead favors answering the given questions and teaching stated rules. She would also follow the same method in writing. She asserts,

Normally I will apply a bit of traditional and a bit of modern in teaching. The traditional part would probably be the grammar, I think they need drilling. That one has to stay as traditional. But in terms in discussion yes that one should be used in the modern which is task-based language teaching. In terms of speaking I think its more suitable for task based. In terms of grammar especially when you are writing it should stay traditional. So 50-50.

On the other hand, she infuses a task based method into her teaching, which she terms a "modern method", in lessons that are related to speaking and discussions, as is the case with debating.

\section{Reasons for Using TBLT in Class}

T1 finds the task based language teaching method to be diverse and productive. Initially, T1's main approach was originally summed up in a communicative method closely related to the task based language teaching method of teaching. From T1's stance, learning scenarios are regarded as a highly valuable asset towards the improving of students' languages in an extensive manner without having to lower the standards of teaching.

I used it because I was interesting in it.. because uu.. learning scenarios would work... I would call it a communicative, I think that was the big umbrella term.

Both second and third teachers recognize that it is compulsory to make use of taskbased learning techniques within their classrooms. In spite of this there is a rather fair amount of struggle in applying it within their classrooms as their students did not welcome and do not appreciate the acute effect it consequently has on their own learning. Most of the students represented in this context are either repeating the same English level to begin with, or are more focused on the final EPT examination.

\section{TBLT \& Acquisition of Language}

In their responses to interview questions, interviewers identified a number of ways through which students could learn by means of task based language teaching. Upon being asked how task based learning could better aid students in acquiring skills in language, the first teacher somewhat maintains that it is difficult to answer the question, and with the response, quoted verbatim: "How do you know? How do you know if after giving them tons of work to do in as well as tasks it will help teaching the language better? How do you know?" He maintains that even if student progress from one level to another, a yardstick for the measure of progress of students is still largely non-existent, particularly with respect to how much of their respective success is on the part of the teachers' contributions. 
In a shift of opinion several minutes following the discussing of this fact and processing answers the researcher in turn returned to him in response, the interview subject suggested that it is somewhat possible to measure the students before and after the task based language teaching is applied and further contrast the findings to levels achieved with the teaching method and then reach a conclusive answer to the question.

The second teacher takes the stand that by means of discussion one learns. In this respect, giving students activities which will make them use transitional words for instance, is an established method in learning the language. In such a manner, the students are able to accomplish not only the task based aspect, but also achieve well in the sphere of language as well.

This relates rather closely to the task based language teaching method of teaching. The third teacher implements the task in his teaching even if it is not solely based. In doing so, he confirms that it could make a difference in the outcome of the students' final semester level.

\section{Conclusion}

The above results show that the teachers had a good knowledge of TBLT, its goals, tasks, etc. They also agreed that TBLT is a form of communicative language teaching. In spite of this the teachers were very cautious about applying TBLT in their classrooms. They are quite new to this approach and it also requires a lot of preparation beforehand. The teachers also mentioned that TBLT might not be the best method for classroom learning as it makes it difficult to assess the learners' task-based performance. Also some of the students are accustomed to or prefer to teacher-centered learning and thus not familiar with TBLT. Overall, the teachers are well aware about the TBLT but not sure about the advantages in their classrooms. So that is why some teachers were to find using a mixed approach i.e. both TBLT and traditional teacher-centered approach. More studies are needed to really grasp the experiences and challenges of TBLT in different ESL environments. This could also be applied to the teaching of other second or foreign languages such as Arabic.

\section{References}

Brown, H. D. (2007). Teaching by Principles. New York: Addison Wesley Longman Inc.

Carless, D. (2004). Issues in Teachers' re-interpretation of a task-based innovation inprimary schools. TESOL Quarterly, 38(4), 639-662.

Clark, J., Lo, Y. C., Hui, M. F., Kam, M., Carless, D., \& Wong, P. M. (1999). An investigation into the development and implementation of the TOC initiative with special

reference to professional competencies, professional development, and resources: Final report. Hong Kong SAR, China: Hong Kong Institute of Education.

Cunningham, P.M., \& Cunningham, J. W., (1992), Making words; Enhancing the invented spelling-decoding connection. The reading teacher, 46, 106-107

Ellis, R. (2003). Task-based language learning and teaching. Oxford: Oxford University Press. 
Jeon, I. (2005). An analysis of task-based materials and performance: Focused on Korean high school English textbooks. English Teaching, 60(2). 87-109.

Jeon, I \& Hahn, J., (2009). Exploring EFL Teachers' Perceptions of Task-Based Language Teaching: A Case Study of Korean Secondary School Classroom Practice, Mokpo National University, Korea.

Ki, W. W. (2000). ICT Applications in Task-Based Learning. In N. Law and et. al. 6. Changing Classrooms \& Changing Schools: A Study of Good Practices in Using ICT in Hong Kong Schools (pp: 79-91). Hong Kong, Friendship Printing Co., Ltd

Li, D. (1998). "It's always more difficult than you plan and image": Teachers' perceived difficulties in introducing the communicative Soo Ha (Sue) Yim 49 approach in South Korea. TESOL Quarterly, 32(4), 677-703.

Li, D. (1998). "It's always more difficult than you plan and image": Teachers' perceived difficulties in introducing the communicative Soo Ha (Sue) Yim 49 approach in South Korea. TESOL Quarterly, 32(4), 677-703.

Littlewood, W. (2004). The Task Based Approach: Some Questions and Suggestions. 8. ELT Journal 58(4), 319-326.

Littlewood, W. (2007). Communicative and task-based language teaching in East Asian classrooms. Language Teaching, 40(3), 243-249.

Malaysian Ministry of Education (MOE). (2003). The Form Five English Language Curriculum Specifications. Retrieved from www.moe.gov.my.

McDonough, K., \& Chaikitmongkol, W. (2007). Teachers' and Learners Reactions to a Task-Based EFL Course in Thailand. TESOL Quarterly, 41 (1), 107-132.

Nunan, D. (1991). Communicative Tasks and the Language Curriculum. TESOL Quarterly, 25 (2), 279-295.

Nunan, D. (1999). Second Language Teaching and Learning. Boston: Heinle / Thompson Learning.Pintrich \& De Groot (1990)

Nunan, D. (2001) Aspects of Task-Based Syllabus Design Aspects of Task-Based Syllabus Design. University of Hong Kong.

Nunan, D. (2003). The impact of English as a global language on educational policies and practices in the Asia-Pacific region. TESOL Quarterly, 37(4), 589-613.

Prabhu, N. (1987). 11. Second language pedagogy. Oxford: Oxford University Press.

Rahman, M. (2010), Teaching Oral Communication Skills: A Task-based Approach. Indian School of Mines University.

Richards, J., \& Rodgers, T. (2001). Approaches and methods in language teaching. Cambridge: Cambridge University Press.

Savignon, S. (2002). Interpreting communicative language teaching. New Haven: Yale University Press.

Skehan, P. (1998). A cognitive approach to language learning. Oxford: Oxford University Press.

Solares, M. E. (2006). TBLT: Challenges and Problems in an Online Course Design for 15. Teacher Development. On line Documents at http://www.tblt.org/download/solares.doc [22.12.2006]Vystavělova 2009

Willis J. (1996). A framework for task-based learning. Essex: Longman/AddisonWesley.

Yim, S. (n. d.). South Korean Teachers' Perceptions of TBLT. Samsung Art and Design Institute. 